\title{
Biophysical Modulations of Functional Connectivity
}

\author{
Scott J. Peltier ${ }^{1,2}$ and Yash Shah ${ }^{2}$
}

\begin{abstract}
Resting-state low frequency oscillations have been detected in many functional magnetic resonance imaging (MRI) studies and appear to be synchronized between functionally related areas. Converging evidence from MRI and other imaging modalities suggest that this activity has an intrinsic neuronal origin. Multiple consistent networks have been found in large populations, and have been shown to be stable over time. Further, these patterns of functional connectivity have been shown to be altered in healthy controls under various physiological challenges. This review will present the biophysical characterization of functional connectivity, and examine the effects of physical state manipulations (such as anesthesia, fatigue, and aging) in healthy controls.
\end{abstract}

Key words: aging; anesthesia; connectivity; fatigue; functional magnetic resonance imaging; modulation; resting-state

\section{Introduction}

$\mathbf{R}$ ECENT STUDIES IN functional magnetic resonance imaging (fMRI) have shown slowly varying time course fluctuations in resting-state data that are temporally correlated between functionally related areas. These fluctuations agree with the concept of functional connectivity: a descriptive measure of spatiotemporal correlations between spatially distinct regions of cerebral cortex (Friston et al., 1993). First shown in the fMRI literature by Biswal et al. (1995), these low-frequency oscillations have been shown to exist in the motor, auditory, visual, sensorimotor, and language systems, among others (Biswal and Ulmer, 1999; Cordes et al., 2000; Hampson et al., 2002; Hyde and Biswal, 2000; Lowe et al., 1998; Xiong et al., 1999). More recently, it has been investigated in the so-called "default-mode" network (Greicius et al., 2003; Raichle et al., 2001).

Studies examining the frequency characteristics have found the primary signal to lie under $0.1 \mathrm{~Hz}$, in the frequency band of the blood oxygen level dependent (BOLD) response, with possible noise sources such as cardiac- and respiratoryinduced noise having a higher frequency response, if sampled adequately (Cordes et al., 2000; De Luca et al., 2006). Further, studies employing multi-echo sequences have examined the T2* dependence of functional connectivity patterns. Our group found the linear echo-time dependence of functional connectivity patterns in the motor cortex to agree with the first-order BOLD signal equation, in the same way as taskinduced activation (Peltier and Noll, 2002). Recently, Bianciardi et al. (2009) used multi-echo data at 7T to examine the relative contributions of possible confounds to the connectivity patterns. They found that after removing confounds, the dominant signal was from spontaneous activity, especially at the region of interest (ROI) level. Thus, both functional connectivity and "regular" task activation seem to arise from the same BOLD-related origins.

A limitation of BOLD fMRI is that it is an indirect measure of neuronal activity. However, research using other imaging modalities suggests that functional connectivity has neuronal origins. For example, in perfusion imaging, functional connectivity patterns have been found using both arterial spin labeling (Chuang et al., 2008) and $\mathrm{CMRO}_{2}$ (Wu et al., 2009). Studies investigating resting correlates using electroencephalogram (EEG) have found that the different resting-state networks can be characterized by their corresponding EEG signatures (Laufs et al., 2003; Mantini et al., 2007). Further, recent animal studies have demonstrated coupling between the resting-state BOLD fluctuations and local neuronal activity employing simultaneous fMRI and neurophysiological recording (Scholvinck et al., 2010; Shmuel and Leopold, 2008), and spatiotemporal organization of resting-state neuronal activity using voltage-sensitive dye imaging (Kenet et al., 2003; Mohajerani et al., 2010). Thus, converging imaging evidence suggests that resting-state functional connectivity has underlying neuronal origins.

Reproducibility studies have shown resting patterns to be consistent over large numbers of healthy controls, repeated over time (Biswal et al., 1997; Shehzad et al., 2009; Van Dijk et al., 2010). This stability allows investigation of changes in resting-state patterns between controls and patients. Several

\footnotetext{
${ }^{1}$ Functional MRI Laboratory, University of Michigan, Ann Arbor, Michigan.

${ }^{2}$ Biomedical Engineering, University of Michigan, Ann Arbor, Michigan.
} 
recent studies have further shown decreased low-frequency correlations in pathological states such as callosal agenesis (Lowe et al., 1997) or Alzheimer's disease (Supekar et al., 2008), where there can be a disruption or degradation of the physical connections in the white matter. Further, restingstate functional MRI has shown differences in a wide variety of patient populations, such as depression (Berman et al., 2010), autism (Monk et al., 2009), and schizophrenia (Lynall et al., 2010). Low-frequency functional connectivity is thus important as a potential indicator of regular neuronal activity within the brain.

Another avenue of investigation is how the functional connectivity patterns change over time in a healthy brain, in response to internal or external modulation. This review will explore the change in resting connectivity under a variety of physiological changes, in the short term (fatigue, learning), medium term (sleep, anesthesia), and long term (development and aging). Finally, some future directions will be discussed.

\section{Physiological Modulation in the Short Term}

The resting-state activity of the brain is a dynamic, not static, entity. The evolving brain state may be influenced by its internal and external stimulus. It has been shown that prior cognitive states can influence subsequent "resting-state" activity (Waites et al., 2005). Experimental manipulations, as well, may modulate connectivity in the short term. For example, Napadow et al. (2008) examined resting-state data before and after acupuncture, and found increased connectivity with pain and memory regions following real, but not sham, acupuncture. This suggests that resting fMRI in the short term may exhibit change due to prior activity. Here, we examine short-term modulation in the specific cases of fatigue and learning.

\section{Fatigue}

Prolonged voluntary muscle fatigue can induce substantial neural signal changes in a number of primary, secondary, and association cortical areas (Liu et al., 2003). The brain can experience a disrupted process not only in processing a large amount of sensory (fatigue) information, but also in continuously forming new commands to drive the fatiguing muscle to maintain desired muscle output. It has been observed that the level of activity of the right and left primary motor cortices can increasingly differ during a repetitive unimanual task (Liu et al., 2003), indicating a fatigue-related disassociation of the two hemispheres. It is also known that recovery from fatigue does not occur immediately (Enoka and Stuart, 1992).

It was investigated whether the neural effects of muscle fatigue persisted after a fatiguing task, using resting-state fMRI (Peltier et al., 2005a). Resting-state acquisitions were acquired before and after a unimanual fatigue task (20 min of repetitive hand clenching) for eight subjects. The interhemispheric cross-correlation was calculated for voxels in the primary motor cortices (see Peltier et al., 2005a for more details). We observed that the resting-state time courses of the primary motor cortices are more dissimilar after the fatigue task (Fig. 1A). Moreover, the amount of significant interhemispheric correlations decreased significantly (Fig. 1B, C). Following the fatigue task, there was a $72 \%$ reduction of significant motor interhemispheric correlations $(p<0.05)$ over all subjects. This demonstrates that resting-state func- tional connectivity can reflect short-term changes in the state of neural networks.

\section{Learning}

Another short-term process that can be investigated with resting-state functional connectivity is learning (e.g., motor learning, perceptual learning). Neural plastic effects induced by training can result in modifications to the brain's function, which can persist after the training itself (Schwartz et al., 2002). The cognitive effects of learning can thus potentially alter resting-state functional connectivity, even after training has ended.

Dynamic changes in connectivity have further been seen in motor or visual learning studies. Albert et al. (2009) acquired resting-state scans before and after an 11 min motor session. Dummy tasks were used in between the motor task and the second resting-state scan. They demonstrated enhancement in frontoparietal circuit following motor learning, but not motor performance. Lewis et al. (2009) showed changes following visual perceptual learning in the visual cortex and frontoparietal areas involved in spatial attention (Fig. 2). By acquiring resting-state data before and after training on a visual shape-identification task constrained to one visual quadrant, they found that resting-state changes between the visual cortex and frontoparietal areas correlated with the degree of perceptual learning. In addition, they found that the effects could extend to visual areas not involved in the training. Taken together, these studies demonstrate that the prolonged effects of processes such as learning may be examined with resting-state functional connectivity.

\section{Physiological Modulation in the Medium Term}

Resting-state patterns are hypothesized to relate to neuronal activity, but their full relationship to conscious processes is not known (Fukunaga et al., 2006). Toward this end, several studies have investigated the effects of varying states of consciousness, including sleep (Fukunaga et al., 2006; Horovitz et al., 2008; Larson-Prior et al., 2009; Spoormaker et al., 2010), sedation and anesthesia (Alkire et al., 2000; Antognini et al., 1997; Boveroux et al., 2010; Kiviniemi et al., 2000; Martuzzi et al., 2010; Peltier et al., 2005b; Ramani et al., 2007; Schrouff et al., 2011), and vegetative states (Boly et al., 2004; Owen et al., 2006). In this section, sleep and anesthesia will be discussed, as reversible examples of physiological modulation in the medium term.

\section{Sleep}

Sleep is a rapidly reversible system-level process, characterized by loss of motor responsiveness, loss of consciousness, and reduced metabolism (Braun et al., 1997; Iber et al., 2007). These suppressive effects are also accompanied by increased memory consolidation (Stickgold, 2005). Stages of sleep include rapid eye movement (REM) and non-REM, which is further classified into multiple sleep stages based on EEG, electrooculography (EOG), and electromyography (EMG) activity (Iber et al., 2007). The reduced states of arousal in sleep afford an opportunity to investigate resting-state fluctuations in the absence of conscious activity (Fukunaga et al., 2006; Horovitz et al., 2008), as well as investigating possible mechanisms of sleep-induced loss of consciousness. 


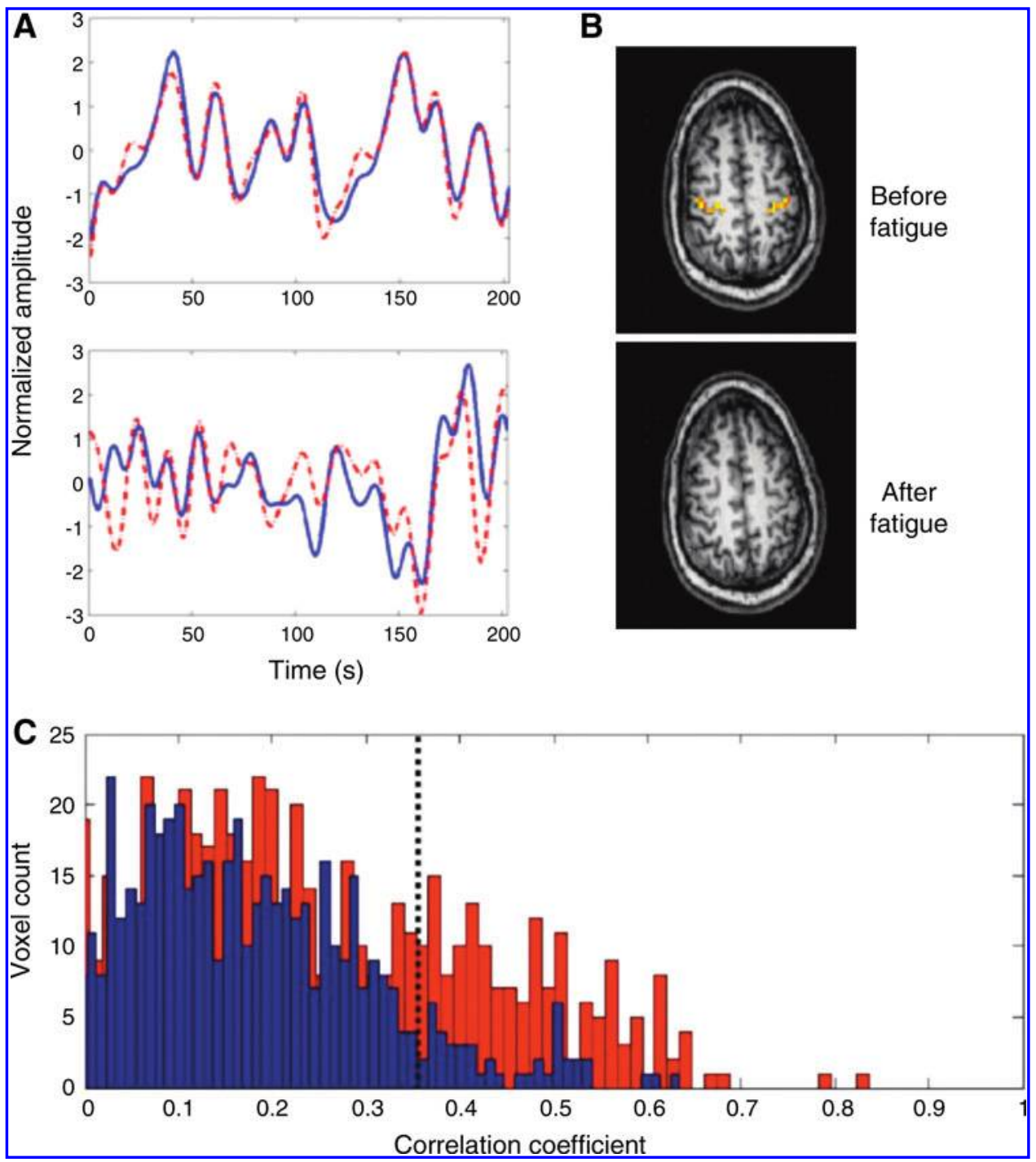

FIG. 1. Example of shortterm modulation of functional connectivity after motor fatigue. (A) Average time courses for the left (blue, solid) and right (red, dashed) motor cortices for a typical subject, before (top) and after (bottom) fatigue. (B) The mean interhemispheric correlation for each voxel in the motor cortex for a typical subject, before and after fatigue. (C) Histogram of the mean interhemispheric correlation values over all subjects $(n=8)$. The dashed line corresponds to the significant threshold of $p<0.05$. The number of significant correlations decreases after the fatigue task. Adapted from Peltier et al. (2005a).

Several studies have examined functional connectivity during awake and sleep states using simultaneous EEG/ fMRI. This allowed simultaneous characterization of the sleep state while acquiring resting-state fMRI data. Fukunaga et al. (2006) found that the resting-state visual network persisted during sleep, and that the levels of signal fluctuation were higher in sleep compared to the awake state, and comparable to levels during visual stimulation. Horovitz et al. (2008) found that the resting-state default-mode activity persisted during light sleep (Fig. 3A). Further, Larson-Prior et al. (2009) found that connectivity in six resting-state networks (attention, default, executive, somatomotor, visual, and auditory) was maintained between awake and light sleep (Fig. 3B). In a recent study, Spoormaker et al. (2010) examined connectivity across sleep stages, and found that there was a loss in thalamic connectivity in moving from wake to sleep states, and a loss in general cortical connectivity in slow-wave sleep. This may help inform further investigations of consciousness.

These studies suggest that the resting-state activity, instead of being undirected conscious thought, does not require active cognitive processes, instead perhaps serving a critical role in cortical system integrity maintenance.

\section{Anesthesia}

Anesthesia is a (hopefully) reversible state of central nervous system suppression. However, the mechanism of anesthesia is not completely understood. Part of the problem is that it is not a uniform entity, and has several physiological endpoints of interest, including ablation of motor responses, memory function, and consciousness (Veselis, 2001). Both the regional suppressive effects on individual brain structures, as well as the global disconnective effects between brain networks, need to be explained (Veselis et al., 2002; White and Alkire, 2003).

Previous studies involving anesthesia-induced unconsciousness have suggested that disrupted thalamocortical networks are a central mechanism (Alkire et al., 2000; Ries and Puil, 1999). White and Alkire (2003) found reduced thalamic activity using halothane and isoflurane. However, Långsjö et al. (2004) found an increase in activity in the thalamus using ketamine as the anesthetic agent. These studies may support a hypothesis that disruption of the thalamocortical network plays a central role in anesthesia-induced unconsciousness.

In our previous work (Peltier et al., 2005b), we examined resting-state functional connectivity at different concentrations 


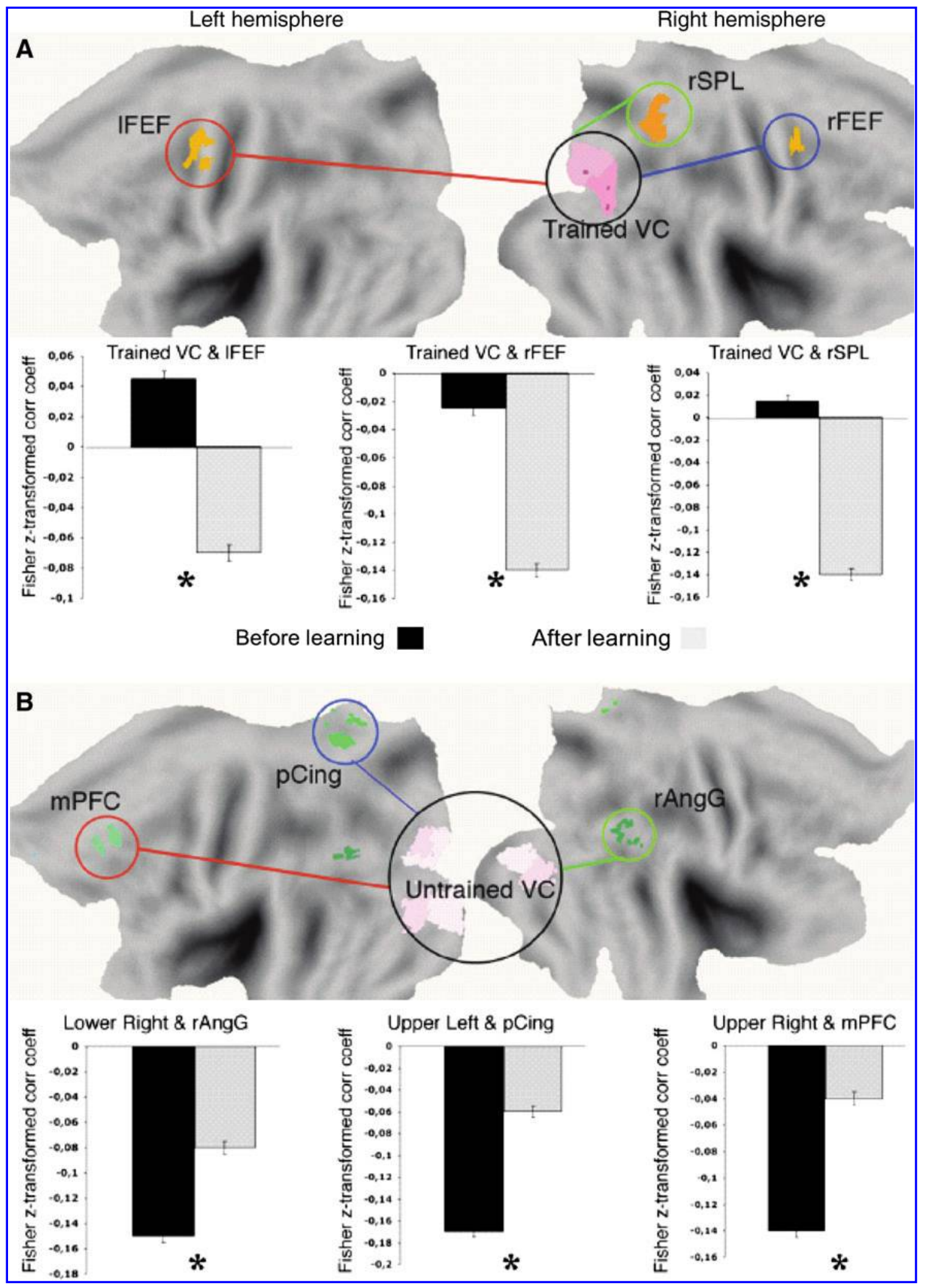

FIG. 2. Modulation of spontaneous functional connectivity after perceptual learning. The task involved training on a shapeidentification task constrained to one visual quadrant. Flattened brain representation with ROIs in trained visual cortex and dorsal attention network (A) and in untrained visual cortex and default network (B). Bar graphs report Pearson correlation coefficients between trained visual cortex and dorsal attention ROIs and untrained visual cortices and default network ROIs before (black) and after (gray) perceptual learning. Two-tail Student's $t$-test, $p<0.05$; error bars \pm SEM. Adapted from Lewis et al. (2009). The asterisk denotes significant difference in the graphed data. 


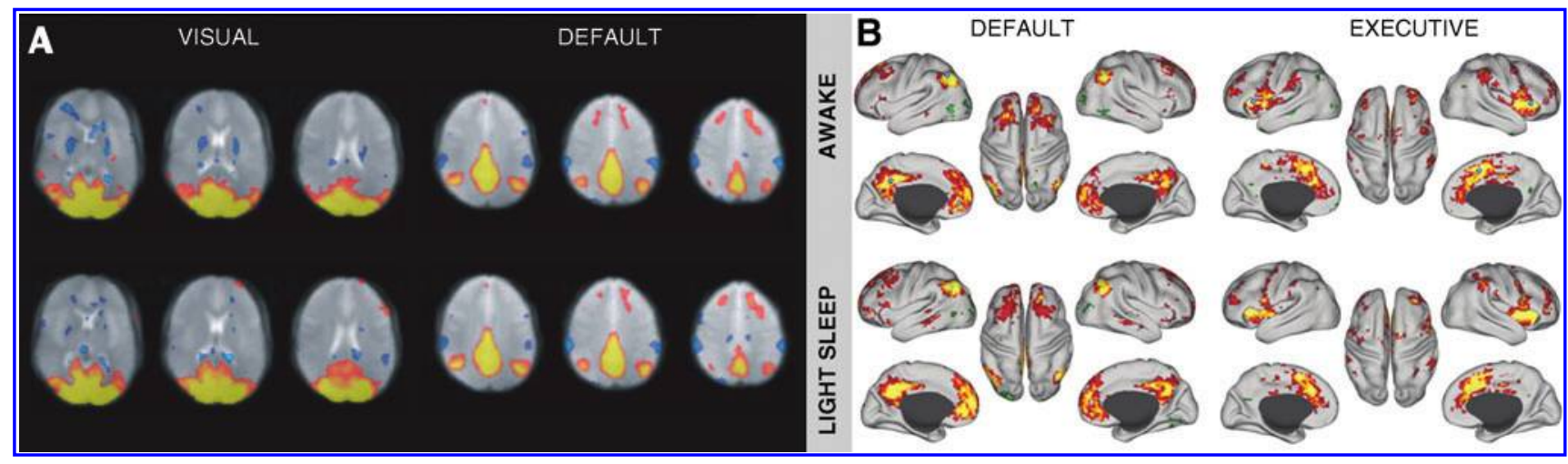

FIG. 3. Comparison of resting-state connectivity maps in awake (top) and light sleep (bottom) states. (A) Statistical composite maps showing temporal correlation with seed time courses in the visual cortex (visual) and posterior cingulate (default). Adapted from Horovitz et al. (2008). (B) Conjunction analysis of cognitive network seed correlations; locations of seed ROIs are located by blue circles. Adapted from Larson-Prior et al. (2009).

of sevoflurane (Fig. 4). By employing gradations of anesthetic influence, we were able to explore the effect of anesthesia on baseline, task-independent connectivity. In particular, changes in the functional connectivity of the motor network were analyzed. We observed a reliable resting-state motor network in the awake condition, as expected from previous studies (Cordes et al., 2000; Lowe et al., 1998; Peltier and Noll, 2002). In the deep anesthetic state, the network was first completely attenuated, and then, after recovering to the light state, the network response was confined to the hemisphere where the motor seed was placed. The observed reduction and recovery of functional connectivity complements previous work by Biswal et al. (1997) showing reversible reductions of functional connectivity during hypercapnia. The loss of temporal synchronization between motor cortices may impair motor performance (Serrien and Brown, 2004), and help to explain the suppressive effect of sevoflurane anesthesia on motor responsiveness (Galinkin et al., 1997; Ibrahim et al., 2001; Serrien and Brown, 2004). The circumscribed functional network during the light anesthetic concentration, as opposed to a global integrated network in the awake state, is reminiscent of reports on anterior-posterior dissociations of synchronized brain activity as measured by surface EEG (Lee et al., 2009).

These studies demonstrate that functional connectivity can be studied under anesthesia, and may be associated with changes in consciousness or network disassociation. Animal studies have also demonstrated coherent resting-state fMRI activity that may be altered under anesthesia (Moeller et al., 2009; Vincent et al., 2007). An open area of investigation is the effect of different anesthetic agents and/or different concentration levels. Results using sevoflurane, propofol, and so on, in humans have varied in the degree and direction of connectivity modulation (Table 1 ). These varied agents may have differing central effects and may be dose dependent (Alkire et al., 2000; Ries and Puil, 1999; Veselis et al., 2002), and thus modulate connectivity differently. Careful examination of agent type and dosage level will help to elucidate this matter further. Multimodal investigations using EEG and CBF

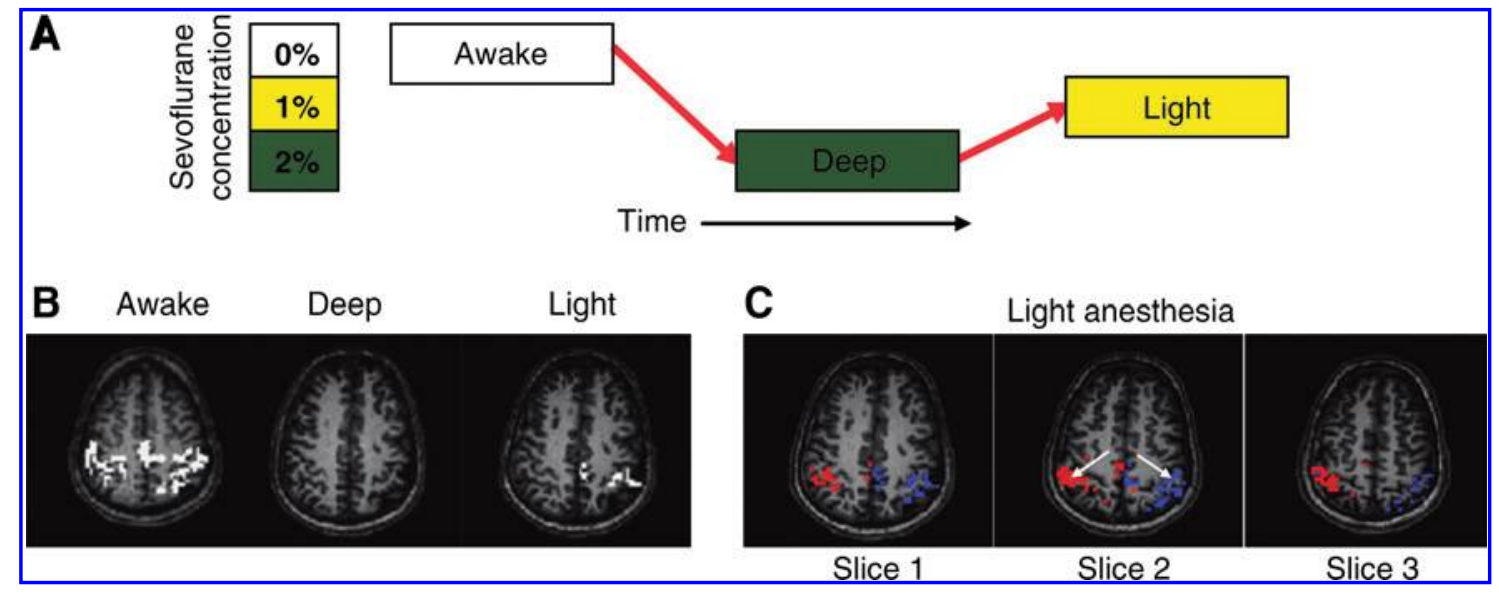

FIG. 4. Modulation of functional connectivity under graded levels of sevoflurane anesthesia. (A) Experimental paradigm; subjects had resting-state fMRI scan in awake state, followed by deep state ( $2 \%$ sevoflurane), followed by light state ( $1 \%$ sevoflurane). Subjects were held constant at each anesthetic level for $15 \mathrm{~min}$ before fMRI acquisition. (B) Functional connectivity results in the motor cortex under the awake, deep, and light states. (C) Functional connectivity results for three contiguous slices in a representative subject under light anesthesia, for left (red) and right (blue) motor cortex seed ROIs. Arrows indicate the location of the seed ROIs. Adapted from Peltier et al. (2005b). fMRI, functional magnetic resonance imaging. 
Table 1. Resting-State Functional Magnetic Resonance Imaging Studies Examining the Effects of Anesthesia in Humans

\begin{tabular}{|c|c|c|}
\hline Author & Anesthetic & Findings \\
\hline $\begin{array}{l}\text { Schrouff } \\
\quad \text { et al. (2011) }\end{array}$ & $1.5-2.8 \mu \mathrm{g} / \mathrm{mL}$ propofol & $\begin{array}{l}\text { Total integration within brain networks was significantly lower } \\
\text { during deep sedation as compared to resting-state wakefulness. }\end{array}$ \\
\hline $\begin{array}{l}\text { Boveroux et al. } \\
\quad(2010)\end{array}$ & $1.5-2.8 \mu \mathrm{g} / \mathrm{mL}$ propofol & $\begin{array}{l}\text { Decrease in consciousness linearly correlated with decreased } \\
\text { corticocortical and thalamocortical connectivity in frontoparietal } \\
\text { networks. }\end{array}$ \\
\hline $\begin{array}{l}\text { Martuzzi } \\
\text { et al. (2010) }\end{array}$ & $\begin{array}{l}1 \% \text { end-tidal } \\
\text { sevoflurane }\end{array}$ & $\begin{array}{l}\text { fc-fMRI patterns did not significantly differ in sensory cortex and } \\
\text { in the DMN, whereas, in high-order cognitive regions (memory } \\
\text { and pain circuits), it was significantly altered by anesthesia. }\end{array}$ \\
\hline $\begin{array}{l}\text { Peltier et al. } \\
\qquad(2005 b)\end{array}$ & $\begin{array}{l}1 \% \text { and } 2 \% \text { end-tidal } \\
\text { sevoflurane }\end{array}$ & $\begin{array}{l}\text { A network involving the primary motor cortex, sensorimotor area, } \\
\text { and SMA was found in the awake state. Connectivity of this } \\
\text { network was diminished under light anesthesia and virtually } \\
\text { absent under deep anesthesia. }\end{array}$ \\
\hline $\begin{array}{l}\text { Kiviniemi } \\
\text { et al. (2000) }\end{array}$ & $\begin{array}{l}6.3 \mathrm{mg} / \mathrm{kg} / \mathrm{h} \\
\text { intravenous } \\
\text { thiopental boluses }\end{array}$ & $\begin{array}{l}\text { Concentrated signal fluctuations were observed near the primary } \\
\text { sensory areas. Thiopental was suspected to cause an increase in } \\
\text { the amplitude and reduction in the frequency of these } \\
\text { fluctuations. }\end{array}$ \\
\hline
\end{tabular}

fMRI, functional magnetic resonance imaging.

measures, while controlling for physiological variables such as blood pressure (Kannurpatti et al., 2003), can also help ascertain the underlying mechanism of anesthesia (Liu et al., 2011). For further review of the effects of anesthesia on functional connectivity, please see Nallasamy and Tsao (2011).

\section{Physiological Modulation in the Long Term}

When considering functional and structural connectivity in younger and older subjects, brain maturation needs to be considered as a factor. Changing white matter and gray matter volumes in early childhood, during adolescence, and in old age can alter the functional and structural networks, with consequent possible age-dependent differences between target groups of interest. It has also been shown that structural and functional connectivity are correlated; a high degree of structural connectivity can imply a higher degree of functional connectivity (Honey et al., 2009; Koch et al., 2002; Skudlarski, et al., 2008; see also Honey et al., 2010 for review). In this section, the effects of development and aging on the resting-state networks are considered.

\section{Development}

Studies investigating human cerebral development have investigated white matter structural changes that occur
FIG. 5. Comparison of resting-state functional connectivity maps in adults and children. Seed region (solid black circle) in mPFC (ventral: -3, 39, -2). (A) Adult connectivity pattern exhibits expected response in defaultmode network. However, the connectivity map in children significantly deviates from that of the adults. Functional connections with regions in the posterior cingulate and lateral parietal regions (highlighted with blue open circles) are present in the adults but absent in children. (B) These qualitative differences between children and adults are confirmed by the direct comparison (random effects) between adults and children. $\mathrm{mPFC}$ (ventral) functional connections with the posterior cingulate and lateral parietal regions are significantly stronger in adults than children. Adapted from Fair et al. (2008).

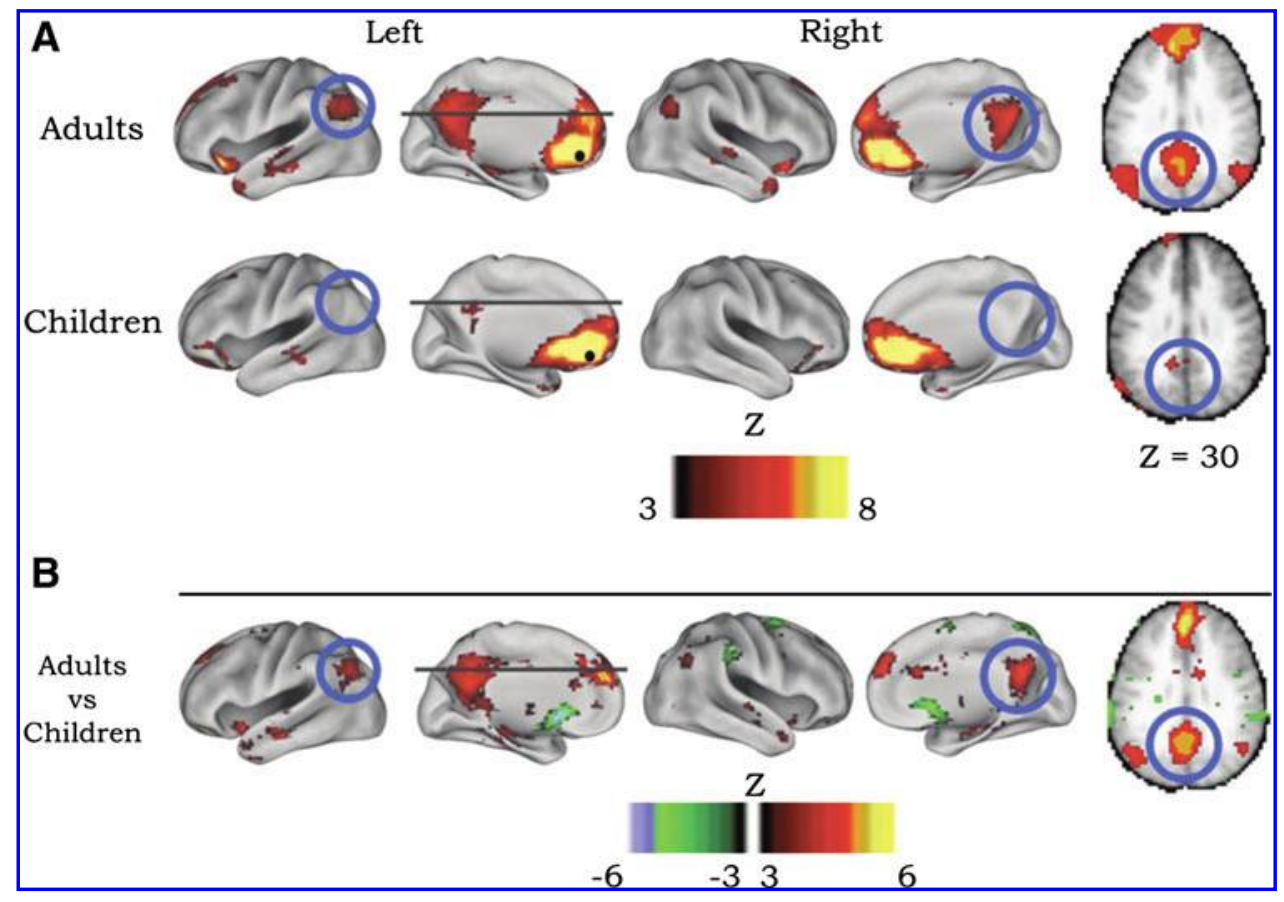

B 
prior to adulthood. White matter volume increases approximately linearly with age until early adulthood, while gray matter volume increases into adolescence, then decreases postpubescence into adulthood (Gogtay et al., 2004; Sowell et al., 2003), with total cerebral volume similar in adults and adolescents (Giedd, 2004; Giedd et al., 1999). These structural changes appear to be region specific, occurring with differing temporal courses across adolescence, with the frontal lobes maturing later than other cortical regions (Romine and Reynolds, 2005). The observed differences arise due to multiple processes including loss of synapses, increases in myelination, and changes in receptor density (e.g., glutamate receptors in the prefrontal cortex) (Giedd et al., 1999; Spear, 2000). In addition, diffusion tensor imaging has demonstrated changes in white matter microstructure (i.e., increased density) with increasing age (Barnea-Goraly et al., 2005; Schneider et al., 2004; Snook et al., 2005).

The developing brain thus has dynamic changes in the underlying structural connectivity that may alter the activity of resting-state networks. Several studies have started to investigate effects of development using fMRI resting-state connectivity. Fransson et al. (2007) found incomplete default-mode networks in infants. Fair et al. (2008) investigated the default-mode network in children of ages 7-9 and in adults of ages 19-31. They found that the network is only loosely connected in children, while being highly integrated in the adult population (Fig. 5). Both these studies indicate a developmental effect on the resting-state brain. Even further, Dosenbach et al. (2010) used resting-state data from over 200 subjects to predict physical age from the resting-state data. Using multivariate pattern analysis, they achieved $92 \%$ accuracy in classifying children from adults, controlling for brain volume and movement, with brain maturity being predicted by weakening of short-range connections between functional networks, and strengthening within networks. This pattern of network "pruning" and consolidation with increasing age may also be accompanied by a reduction in power of the resting-state fluctuations (Littow et al., 2010).

\section{Aging}

Cortical aging brings reductions in memory, inhibitory control, and processing speed. These may be the results of neurotransmitter receptor depletion, gray matter atrophy, and white matter deterioration (Reuter-Lorenz and Cappell, 2008). Gray matter decreases with age, with regionally variant losses, with increased reductions in the frontal lobes (Good et al., 2001; Jernigan et al., 2001; Raz et al., 1997). Age-associated white matter loss and/or demyelination can also lead to cognitive decline (O'Sullivan et al., 2001; Pfefferbaum and Sullivan, 2004).

Functional MRI aging studies have begun to apply MR connectivity to examine age-related declines. AndrewsHanna et al. (2007) showed reductions in the default-mode network and dorsal attention network during a semantic task in older subjects, compared to younger subjects (Fig. 6). These reductions were associated with white matter degradation and reduced functional performance, and were present even in those older subjects screened against having preclinical Alzhiemer's disease. Following this, Damoiseaux et al. (2008) reported reduced activity in the default-mode network for

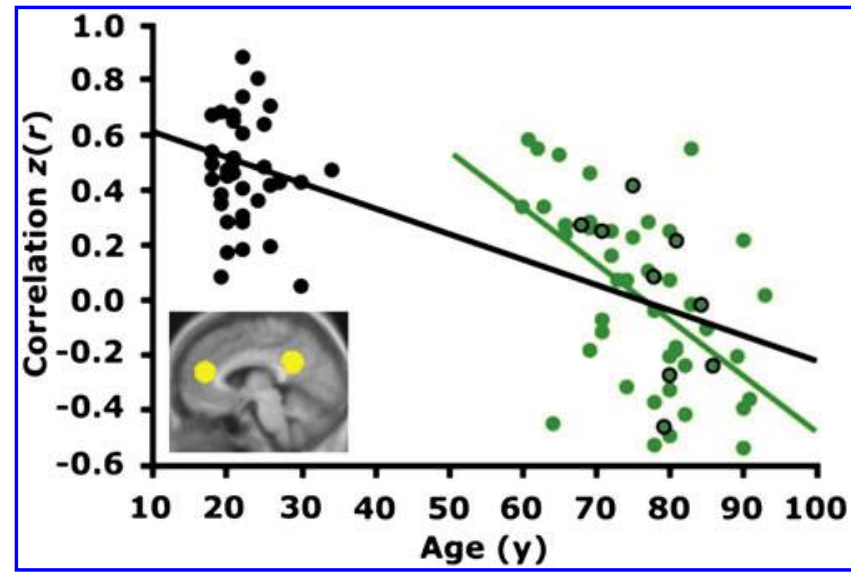

FIG. 6. Reduction of anterior to posterior functional correlations with aging. The time course within the medial prefrontal cortex (mPFC) was correlated with the time course within the posterior cingulate/retrosplenial cortex $(\mathrm{pC} / \mathrm{rsp})$ for young (black) and old (green) participants. The resulting z-transformed correlation coefficient $\mathrm{z}(r)$ for each participant is plotted against age. The black regression line, shown for illustrative purposes only, indicates a strong negative relationship between anterior-posterior functional correlations and age across both groups. The green regression line indicates a negative relationship with age in the older group alone $(r=-0.53, p<0.001)$. Green data points outlined in black represent individuals without amyloid beta deposition as determined by positron emission tomography. Adapted from Andrews-Hanna et al. (2007).

older versus younger subjects. In addition, they correlated this reduction with age and reduced processing speed in the older subjects. Langan et al. (2010) demonstrated increased interhemispheric connectivity in the bilateral motor network. This correlated with increased bilateral recruitment during a motor task in older adults, suggesting loss of interhemispheric inhibition (please see Fling et al., 2011, for further discussion). These studies suggest that alterations to brain network connectivity may play an important role in gauging the effect of physical aging.

\section{Discussion}

The physiological manipulations discussed in this review have modulations of functional connectivity over a range of time scales. It is likely that the underlying biophysical mechanism in each case may be different. In the short term, tasks such as fatigue and learning may affect cortical excitability, which in turn may suppress or enhance network communication (Lewis et al., 2009; Peltier et al., 2005a). The medium-term effects of anesthesia can involve neural activity, metabolism, and neurovascular coupling (Liu et al., 2011; Williams et al., 2010), leading to both suppressive and disconnective effects on functional networks (Alkire et al., 2000; Peltier et al., 2005b). Finally, the effects of development and aging may reflect the long-term changes in white matter connectivity. Further work may better define the time signature of these different biophysical processes, and their resultant effect on spontaneous functional connectivity patterns.

In addition to time-dependent signals of interest, there are also potential time-varying confounds in resting-state functional MRI. Cardiac- and respiration-induced variations can 
cause artifacts in resting-state analyses (Birn et al., 2006). Changes in blood pressure can also alter the resting-state fluctuations (Kannurpatti et al., 2003). In addition, time-varying psychological processes such as mental fatigue should be considered when designing resting-state experiments.

Resting-state functional connectivity is an emergent field, with continual refinement of techniques. Besides the seed correlation method that is used in a large number of studies, datadriven approaches can also be used to detect resting-state networks with reduced user bias (Beckmann and Smith, 2004; Calhoun et al., 2008; Peltier et al., 2003). Additionally, new acquisitions that can acquire brain volumes with subsecond TRs can also help with separating out physiological noise, as well as acquire data with greater temporal degrees of freedom (Feinberg et al., 2010). The dynamic nature of functional connectivity networks may also be exploited further. As noted in Chang and Glover (2009), functional networks are a dynamic entity, with temporal variations and changing spatial associations over the time course of an fMRI scan. Applying real-time and pattern classification approaches (LaConte et al., 2005, 2007) in the monitoring of these dynamic changes may help to explore the full range of resting-state activity. Advances in all of these areas will help to increase the sensitivity and accuracy of resting-state analyses.

\section{Conclusion}

Resting-state MRI functional connectivity seems to arise from ongoing spontaneous brain activity; thus, low-frequency functional connectivity is important as an indicator of normal neuronal activity. This review has dealt with physiologic changes in functional connectivity in healthy brains, and demonstrated that resting-state connectivity can monitor physiological changes in the short, medium, and long term. Application of these same techniques to patient populations and animal studies can help develop to better characterize disease states, functional loss and recovery, and develop predictive imaging biomarkers of disease states (Craddock et al., 2009).

\section{Acknowledgments}

The authors would like to thank Dr. Stephen LaConte (Virginia Tech), Dr. Cameron Craddock (Virginia Tech), and Dr. Rachael Seidler (University of Michigan) for helpful discussions and also the anonymous reviewers for their constructive criticism.

\section{Author Disclosure Statement}

The authors have no conflicts of interest to declare.

\section{References}

Albert NB, Robertson EM, Miall RC. 2009. The resting human brain and motor learning. Curr Biol 19:1023-1027.

Alkire MT, Haier RJ, Fallon JH. 2000. Toward a unified theory of narcosis: brain imaging evidence for a thalamocortical switch as the neurophysiologic basis of anesthetic-induced unconsciousness. Conscious Cogn 9:370-386.

Andrews-Hanna JR, Snyder AZ, Vincent JL, Lustig C, Head D, Raichle ME, Buckner RL. 2007. Disruption of large-scale brain systems in advanced aging. Neuron 56:924-935.
Antognini JF, Buonocore MH, Disbrow EA, Carstens E. 1997. Isoflurane anesthesia blunts cerebral responses to noxious and innocuous stimuli: a fMRI study. Life Sci 61:PL349-54.

Barnea-Goraly N, Menon V, Eckert M, Tamm L, Bammer R, Karchemskiy A, Dant CC, Reiss AL. 2005. White matter development during childhood and adolescence: a crosssectional diffusion tensor imaging study. Cereb Cortex 15:1848.

Beckmann CF, Smith SM. 2004. Probabilistic independent component analysis for functional magnetic resonance imaging. IEEE Trans Med Imaging 23:137-152.

Berman MG, Peltier S, Nee DE, Kross E, Deldin PJ, Jonides J. 2010. Depression, rumination and the default network. Soc Cogn Affect Neurosci [Epub ahead of print]; doi:10.1093/scan/ nsq080.

Bianciardi M, Fukunaga M, van Gelderen P, Horovitz SG, de Zwart JA, Shmueli K, Duyn JH. 2009. Sources of functional magnetic resonance imaging signal fluctuations in the human brain at rest: a $7 \mathrm{~T}$ study. Magn Reson Imaging 27: 1019-1029.

Birn RM, Diamond JB, Smith MA, Bandettini PA. 2006. Separating respiratory-variation-related fluctuations from neuronal-activity-related fluctuations in fMRI. Neuroimage 31:1536-1548.

Biswal BB, Hudetz AG, Yetkin FZ, Haughton VM, Hyde JS. 1997. Hypercapnia reversibly suppresses low-frequency fluctuations in the human motor cortex during rest using echo-planar MRI. J Cereb Blood Flow Metab 17:301-308.

Biswal BB, Ulmer JL. 1999. Blind source separation of multiple signal sources of fMRI data sets using independent component analysis. J Comput Assist Tomogr 23:265.

Biswal BB, Yetkin FZ, Haughton VM, Hyde JS. 1995. Functional connectivity in the motor cortex of resting human brain using echo-planar MRI. Magn Reson Med 34:537-541.

Boly M, Faymonville ME, Peigneux P, Lambermont B, Damas P, Del Fiore G, Degueldre C, Franck G, Luxen A, Lamy M. 2004. Auditory processing in severely brain injured patients: differences between the minimally conscious state and the persistent vegetative state. Arch Neurol 61:233.

Boveroux P, Vanhaudenhuyse A, Bruno MA, Noirhomme Q, Lauwick S, Luxen A, Degueldre C, Plenevaux A, Schnakers C, Phillips C. 2010. Breakdown of within-and betweennetwork resting state functional magnetic resonance imaging connectivity during propofol-induced loss of consciousness. Anesthesiology 113:1038.

Braun AR, et al. 1997. Regional cerebral blood flow throughout the sleep-wake cycle. Brain 120:1173-1197.

Calhoun VD, Kiehl KA, Pearlson GD. 2008. Modulation of temporally coherent brain networks estimated using ICA at rest and during cognitive tasks. Hum Brain Mapp 29:828-838.

Chang C, Glover GH. 2010. Time-frequency dynamics of restingstate brain connectivity measured with fMRI. Neuroimage 50:81-98.

Chuang KH, et al. 2008. Mapping resting-state functional connectivity using perfusion MRI. Neuroimage 40:1595-1605.

Cordes D, Haughton VM, Arfanakis K, Wendt GJ, Turski PA, Moritz CH, Quigley MA, Meyerand ME. 2000. Mapping functionally related regions of brain with functional connectivity MR imaging. Am J Neuroradiol 21:1636.

Craddock RC, Holtzheimer III PE, Hu XP, Mayberg HS. 2009. Disease state prediction from resting state functional connectivity. Magn Reson Med 62:1619-1628.

Damoiseaux J, Beckmann C, Arigita E, Barkhof F, Scheltens P, Stam C, Smith S, Rombouts S. 2008. Reduced resting-state 
brain activity in the "default network" in normal aging. Cereb Cortex 18:1856.

De Luca M, Beckmann C, De Stefano N, Matthews P, Smith S. 2006. fMRI resting state networks define distinct modes of long-distance interactions in the human brain. Neuroimage 29:1359-1367.

Dosenbach NUF, Nardos B, Cohen AL, Fair DA, Power JD, Church JA, Nelson SM, Wig GS, Vogel AC, Lessov-Schlaggar CN. 2010. Prediction of individual brain maturity using fMRI. Science 329:1358.

Enoka RM, Stuart DG. 1992. Neurobiology of muscle fatigue. J Appl Physiol 72:1631.

Fair DA, Cohen AL, Dosenbach NUF, Church JA, Miezin FM, Barch DM, Raichle ME, Petersen SE, Schlaggar BL. 2008. The maturing architecture of the brain's default network. Proc Natl Acad Sci USA 105:4028.

Feinberg DA, Moeller S, Smith SM, Auerbach E, Ramanna S, Glasser MF, Miller KL, Ugurbil K, Yacoub E. 2010. Multiplexed echo planar imaging for sub-second whole brain FMRI and fast diffusion imaging. PLoS One 5:e15710.

Fling BW, Chapekis M, Reuter-Lorenz PA, Anguera J, Bo J, Langan J, Welsh RC, Seidler RD. 2011. Age differences in callosal contributions to cognitive processes. Neuropsychologia 49:2564-2569.

Fransson P, Skiöld B, Horsch S, Nordell A, Blennow M, Lagercrantz H, Aden U. 2007. Resting-state networks in the infant brain. Proc Natl Acad Sci USA 104:15531.

Friston KJ, Frith CD, Frackowiak RSJ. 1993. Time-dependent changes in effective connectivity measured with PET. Hum Brain Mapp 1:69-79.

Fukunaga M, Horovitz SG, van Gelderen P, de Zwart JA, Jansma JM, Ikonomidou VN, Chu R, Deckers RHR, Leopold DA, Duyn JH. 2006. Large-amplitude, spatially correlated fluctuations in BOLD fMRI signals during extended rest and early sleep stages. Magn Reson Imaging 24:979-992.

Galinkin JL, Janiszewski D, Young CJ, Klafta JM, Klock PA, Coalson DW, Apfelbaum JL, Zacny JP. 1997. Subjective, psychomotor, cognitive, and analgesic effects of subanesthetic concentrations of sevoflurane and nitrous oxide. Anesthesiology 871082.

Giedd JN. 2004. Structural magnetic resonance imaging of the adolescent brain. Ann NY Acad Sci 1021:77-85.

Giedd JN, Blumenthal J, Jeffries NO, Castellanos FX, Liu H, Zijdenbos A, Paus T, Evans AC, Rapoport JL. 1999. Brain development during childhood and adolescence: a longitudinal MRI study. Nat Neurosci 2:861-862.

Gogtay N, Giedd JN, Lusk L, Hayashi KM, Greenstein D, Vaituzis AC, Nugent TF, Herman DH, Clasen LS, Toga AW. 2004. Dynamic mapping of human cortical development during childhood through early adulthood. Proc Natl Acad Sci USA 101:8174.

Good CD, Johnsrude IS, Ashburner J, Henson RNA, Friston KJ, Frackowiak RSJ. 2001. A voxel-based morphometric study of ageing in 465 normal adult human brains. Neuroimage 14:21-36.

Greicius MD, Krasnow B, Reiss AL, Menon V. 2003. Functional connectivity in the resting brain: a network analysis of the default mode hypothesis. Proc Natl Acad Sci USA 100:253.

Hampson M, Peterson BS, Skudlarski P, Gatenby JC, Gore JC. 2002. Detection of functional connectivity using temporal correlations in MR images. Hum Brain Mapp 15:247-262.

Honey CJ, Sporns O, Cammoun L, Gigandet X, Thiran JP, Meuli R, Hagmann P. 2009. Predicting human resting-state func- tional connectivity from structural connectivity. PNAS 106: 2035-2040.

Honey CJ, Thivierge JP, Sporns O. 2010. Can structure predict function in the human brain? Neuroimage 52:766-776.

Horovitz SG, Fukunaga M, de Zwart JA, van Gelderen P, Fulton SC, Balkin TJ, Duyn JH. 2008. Low frequency BOLD fluctuations during resting wakefulness and light sleep: a simultaneous EEG-fMRI study. Hum Brain Mapp 29:671-682.

Hyde J, Biswal B. 2000. Functionally related correlation in the noise. In: Moonen CT, Bandettini PA (eds.) Functional MRI. Berlin: Springer-Verlag; p. 263.

Iber C, Ancoli-Israel S, Chesson AL, Quan SF. 2007. The AASM Manual for the Scoring of Sleep and Associated Events. Westchester, IL: American Academy of Sleep Medicine.

Ibrahim AE, Taraday JK, Kharasch ED. 2001. Bispectral index monitoring during sedation with sevoflurane, midazolam, and propofol. Anesthesiology 95:1151.

Jernigan TL, Archibald SL, Fennema-Notestine C, Gamst AC, Stout JC, Bonner J, Hesselink JR. 2001. Effects of age on tissues and regions of the cerebrum and cerebellum. Neurobiol Aging 22:581-594.

Kannurpatti SS, Biswal BB, Hudetz AG. MAP Reversibly Modulates Resting State fMRI Low-Frequency Fluctuations in Anesthetized Rats. In Proceedings of the 11th Annual Meeting of ISMRM, Toronto, Ontario, Canada, 2003, p. 1856.

Kenet T, Bibitchkov D, Tsodyks M, Grinvald A, Arieli A. 2003. Spontaneously emerging cortical representations of visual attributes. Nature 425:954-956.

Kiviniemi V, Jauhiainen J, Tervonen O, Pääkkö E, Oikarinen J, Vainionpää V, Rantala H, Biswal B. 2000. Slow vasomotor fluctuation in fMRI of anesthetized child brain. Magn Reson Med 44:373-378.

Koch MA, Norris DG, Hund-Georigadis M. 2002. An investigation of functional and anatomical connectivity using magnetic resonance imaging. Neuroimage 16:241-250.

LaConte S, Strother S, Cherkassky V, Anderson J, Hu X. 2005. Support vector machines for temporal classification of block design fMRI data. Neuroimage 26:317-329.

LaConte SM, Peltier SJ, Hu XP. 2007. Real-time fMRI using brain—state classification. Hum Brain Mapp 28:1033-1044.

Langan J, Peltier SJ, Bo J, Fling BW, Welsh RC, Seidler RD. 2010. Functional implications of age differences in motor system connectivity. Front Syst Neurosci 4:17.

Långsjö JW, Salmi E, Kaisti KK, Aalto S, Hinkka S, Aantaa R, Oikonen V, Viljanen T, Kurki T, Silvanto M. 2004. Effects of subanesthetic ketamine on regional cerebral glucose metabolism in humans. Anesthesiology 100:1065.

Larson-Prior LJ, Zempel JM, Nolan TS, Prior FW, Snyder AZ, Raichle ME. 2009. Cortical network functional connectivity in the descent to sleep. Proc Natl Acad Sci USA 106:4489.

Laufs H, Krakow K, Sterzer P, Eger E, Beyerle A, Salek-Haddadi A, Kleinschmidt A. 2003. Electroencephalographic signatures of attentional and cognitive default modes in spontaneous brain activity fluctuations at rest. Proc Natl Acad Sci USA 100:11053.

Lee UC, Mashour GA, Kim S, Noh GJ, Choi BM. 2009. Propofol induction reduces the capacity for neural information integration: implications for the mechanism of consciousness and general anesthesia. Conscious Cogn 18:56-64.

Lewis CM, Baldassarre A, Committeri G, Romani GL, Corbetta M. 2009. Learning sculpts the spontaneous activity of the resting human brain. Proc Natl Acad Sci USA 106:17558.

Littow H, Elseoud AA, Haapea M, Isohanni M, Moilanen I, Mankinen, K, Nikkinen J, Rahko J, Rantala H, Remes J, Starck T, 
Tervonen O, Veijola J, Beckmann C, Kiviniemi VJ. 2010. Agerelated differences in functional nodes of the brain cortex-a high model order group ICA study. Front Syst Neurosci 4:32.

Liu JZ, Shan ZY, Zhang LD, Sahgal V, Brown RW, Yue GH. 2003. Human brain activation during sustained and intermittent submaximal fatigue muscle contractions: an FMRI study. J Neurophysiol 90:300.

Liu X, Zhu XH, Zhang Y, Chen W. 2011. Neural origin of spontaneous hemodynamic fluctuations in rats under burstsuppression anesthesia condition. Cereb Cortex 21:374-384.

Lowe MJ, Davidson RJ, Orendi J. Intra-Hemispheric Functional Connectivity of FMRI Physiological Noise Correlations: Dependence on Attention. In Proceedings of the 5th ISMRM, Vancouver. 1997, p. 1688.

Lowe MJ, Mock BJ, Sorenson JA. 1998. Functional connectivity in single and multislice echoplanar imaging using resting-state fluctuations. Neuroimage 7:119-132.

Lynall ME, Bassett DS, Kerwin R, McKenna PJ, Kitzbichler M, Muller U, Bullmore E. 2010. Functional connectivity and brain networks in schizophrenia. J Neurosci 30:9477.

Mantini D, Perrucci MG, Del Gratta C, Romani GL, Corbetta M. 2007. Electrophysiological signatures of resting state networks in the human brain. Proc Natl Acad Sci USA 104: 13170.

Martuzzi R, Ramani R, Qiu M, Rajeevan N, Constable RT. 2010. Functional connectivity and alterations in baseline brain state in humans. Neuroimage 49:823-834.

Moeller S, Nallasamy N, Tsao DY, Freiwald WA. 2009. Functional connectivity of the macaque brain across stimulus and arousal states. J Neurosci 29:5897.

Mohajerani MH, McVea DA, Fingas M, Murphy TA. 2010. Mirrored bilateral slow-wave cortical activity within local circuits revealed by fast bihemispheric voltage-sensitive dye imaging in anesthetized and awake mice. I Neurosci 30: 3745-3751.

Monk CS, Peltier SJ, Wiggins JL, Weng SJ, Carrasco M, Risi S, Lord C. 2009. Abnormalities of intrinsic functional connectivity in autism spectrum disorders. Neuroimage 47:764-772.

Nallasamy N, Tsao DY. 2011. Functional connectivity in the brain: effects of anesthesia. Neuroscientist 17:94.

Napadow V, Ahn A, Longhurst J, Lao L, Stener-Victorin E, Harris R, Langevin HM. 2008. The status and future of acupuncture mechanism research. J Altern Complement Med 14:861-869.

O'Sullivan M, Jones D, Summers P, Morris R, Williams S, Markus H. 2001. Evidence for cortical "disconnection" as a mechanism of age-related cognitive decline. Neurology 57:632.

Owen AM, Coleman MR, Boly M, Davis MH, Laureys S, Pickard JD. 2006. Detecting awareness in the vegetative state. Science 313:1402.

Peltier SJ, Kerssens C, Hamann SB, Sebel PS, Byas-Smith M, Hu X. 2005b. Functional connectivity changes with concentration of sevoflurane anesthesia. Neuroreport 16:285.

Peltier SJ, LaConte SM, Niyazov DM, Liu JZ, Sahgal V, Yue GH, $\mathrm{Hu}$ XP. 2005a. Reductions in interhemispheric motor cortex functional connectivity after muscle fatigue. Brain Res 1057: $10-16$.

Peltier SJ, Noll DC. 2002. T2* dependence of low frequency functional connectivity. Neuroimage 16:985-992.

Peltier SJ, Polk TA, Noll DC. 2003. Detecting low-frequency functional connectivity in fMRI using a self-organizing map (SOM) algorithm. Hum Brain Mapp 20:220-226.

Pfefferbaum A, Sullivan EV. 2004. Disruption of brain white matter microstructure by excessive intracellular and extracellular fluid in alcoholism: evidence from diffusion tensor imaging. Neuropsychopharmacology 30:423-432.

Raichle ME, MacLeod AM, Snyder AZ, Powers WJ, Gusnard DA, Shulman GL. 2001. A default mode of brain function. Proc Natl Acad Sci USA 98:676.

Ramani R, Qiu M, Constable RT. 2007. Sevoflurane 0.25 MAC preferentially affects higher order association areas: a functional magnetic resonance imaging study in volunteers. Anesth Analg 105:648.

Raz N, Gunning F, Head D, Dupuis J, McQuain J, Briggs S, Loken W, Thornton A, Acker J. 1997. Selective aging of the human cerebral cortex observed in vivo: differential vulnerability of the prefrontal gray matter. Cereb Cortex 7:268.

Reuter-Lorenz PA, Cappell KA. 2008. Neurocognitive aging and the compensation hypothesis. Curr Dir Psychol Sci 17:177.

Ries CR, Puil E. 1999. Mechanism of anesthesia revealed by shunting actions of isoflurane on thalamocortical neurons. J Neurophysiol 81:1795.

Romine CB, Reynolds CR. 2005. A model of the development of frontal lobe functioning: findings from a meta-analysis. Appl Neuropsychol 12:190-201.

Schneider J, Il'yasov K, Hennig J, Martin E. 2004. Fast quantitative diffusion-tensor imaging of cerebral white matter from the neonatal period to adolescence. Neuroradiology 46: 258-266.

Scholvinck ML, Maier A, Ye FQ, Duyn JH, Leopold DA. 2010. Neural basis of global resting-state fMRI activity. PNAS 107:10238-10243.

Schrouff J, Perlbarg V, Boly M, Marrelec G, Boveroux P, Vanhaudenhuyse A, Bruno MA, Laureys S, Phillips C, Pélégrini-Issac M. 2011. Brain functional integration decreases during propofol-induced loss of consciousness. Neuroimage 57:198-205.

Schwartz S, Maquet P, Frith C. 2002. Neural correlates of perceptual learning: a functional MRI study of visual texture discrimination. Proc Natl Acad Sci USA 99:17137.

Serrien DJ, Brown P. 2004. Changes in functional coupling patterns during bimanual task performance. Neuroreport 15:1387.

Shehzad Z, Kelly AM, Reiss PT, Gee DG, Gotimer K, Uddin LQ, Lee SH, Margulies DS, Roy AK, Biswal BB. 2009. The resting brain: unconstrained yet reliable. Cereb Cortex 19:2209.

Shmuel A, Leopold DA. 2008. Neuronal correlates of spontaneous fluctuations in fMRI signals in monkey visual cortex: implications for functional connectivity at rest. Hum Brain Mapp 29:751-761.

Skudlarski P, Jagannathan K, Calhoun VD, Hampson M, Skudlarska BA, Pearlson G. 2008. Measuring brain connectivity: diffusion tensor imaging validates resting state temporal correlations. Neuroimage 43:554-561.

Snook L, Paulson LA, Roy D, Phillips L, Beaulieu C. 2005. Diffusion tensor imaging of neurodevelopment in children and young adults. Neuroimage 26:1164-1173.

Sowell ER, Peterson BS, Thompson PM, Welcome SE, Henkenius AL, Toga AW. 2003. Mapping cortical change across the human life span. Nat Neurosci 6:309-315.

Spear LP. 2000. The adolescent brain and age-related behavioral manifestations. Neurosci Biobehav Rev 24:417-463.

Spoormaker VI, Schröter MS, Gleiser PM, Andrade KC, Dresler M, Wehrle R, Sämann PG, Czisch M. 2010. Development of a large-scale functional brain network during human nonrapid eye movement sleep. J Neurosci 30:11379.

Stickgold R. 2005. Memory consolidation and reconsolidation: what is the role of sleep?. Trends Neurosci 28:408-415. 
Supekar K, Menon V, Rubin D, Musen M, Greicius MD. 2008. Network analysis of intrinsic functional brain connectivity in alzheimer's disease. PLoS Comput Biol 4:e1000100.

Van Dijk KRA, Hedden T, Venkataraman A, Evans KC, Lazar SW, Buckner RL. 2010. Intrinsic functional connectivity as a tool for human connectomics: theory, properties, and optimization. J Neurophysiol 103:297.

Veselis RA. 2001. Anesthesia-a descent or a jump into the depths? Conscious Cogn 10:230-235; discussion 246-258.

Veselis RA, Reinsel RA, Feshchenko VA, Dnistrian AM. 2002. A neuroanatomical construct for the amnesic effects of propofol. Anesthesiology 97:329.

Vincent JL, Patel GH, Fox MD, Snyder AZ, Baker JT, Van Essen DC, Zempel JM, Snyder LH, Corbetta M, Raichle ME. 2007. Intrinsic functional architecture in the anaesthetized monkey brain. Nature 447:83-86.

Waites AB, Stanislavsky A, Abbott DF, Jackson GD. 2005. Effect of prior cognitive state on resting state networks measured with functional connectivity. Hum Brain Mapp 24:59-68.

White NS and Alkire MT. 2003. Impaired thalamocortical connectivity in humans during general-anesthetic-induced unconsciousness. Neuroimage 19:402-411.
Williams KA, Magnuson M, Majeed W, LaConte SM, Peltier SJ, $\mathrm{Hu}$ X, Keilholz SD, 2010. Comparison of [alpha]-chloralose, medetomidine and isoflurane anesthesia for functional connectivity mapping in the rat. Magn Reson Imaging 28:9951003.

Wu CW, Gu H, Lu H, Stein EA, Chen JH, Yang Y. 2009. Mapping functional connectivity based on synchronized $\mathrm{CMRO} 2$ fluctuations during the resting state. Neuroimage 45:694-701.

Xiong J, Parsons LM, Gao JH, Fox PT. 1999. Interregional connectivity to primary motor cortex revealed using MRI resting state images. Hum Brain Mapp 8:151-156.

Address correspondence to:

Scott J. Peltier

Functional MRI Laboratory

University of Michigan

1088 BIRB

2360 Bonisteel Boulevard Ann Arbor, MI 48109

E-mail: spelt@umich.edu 
